\title{
Radiation Exposure to a Physician Performing Flouroscopically Guided Cau- dal Epidural Steroid Injections
}

\author{
Kenneth P. Botwin, MD*, Eric D. Freeman, DO, Robert D. Gruber, DO, Francisco M. Torres-Ramos, \\ MD, Constantine G. Bouchlas, MD, Joseph T. Sanelli, DO, and Ashraf F. Hanna, MD
}

This study was designed to investigate radiation exposure to a physician performing fluoroscopically guided caudal epidural steroid injections. The prospective study design included 100 consecutive fluoroscopically guided caudal epidural steroid injections performed on patients with radiculitis from either herniated nucleus pulposus or lumbar spinal stenosis.

Radiation exposure was monitored with the assistance of a radiological technologist (RT) who allocated four dosimetry badges to all physicians performing fluoroscopically guided caudal epidural steroid injections on consecutive patients being treated for radicular pain. The badges were placed on the ring finger, glasses and both the inside and outside of the lead apron worn by the physician. In addition, the RTs also wore a marked badge outside his/her lead apron. A control badge was placed 67 inches away from the fluoroscopy table, and a second control badge was located in a desk over 500 feet away from the procedure, to monitor ambient radiation.
The average fluoroscopy time per procedure was $12.55 \mathrm{sec}-$ onds. The average/cumulative exposure per procedure was 4.10/410 mREM at the "ring" badge, 2.47/247 mREM at the "glasses" badge, 3.98/398 mREM at the "outside apron" badge and 0.15/15 mREM at the "inside" apron; no radiation was detectable at the "outside room" control badge. The RT's average exposure during these procedures was below the limit of detectability.

Radiation exposure to the physician needs to be considered and minimized in the performance of spinal interventional procedures. Our study demonstrates that radiation exposure to the physician performing fluoroscopically guided caudal epidural steroid injections is well within safety limits when he/she adheres to proper technique.

Keywords: Caudal epidural steroid injections, fluoroscopy, radiation safety
Fluoroscopically guided caudal epidural steroid injections are commonly utilized in the treatment of bilateral lumbosacral radiculitis. The methodology and efficacy of this procedure have been reviewed elsewhere $(1,2,3)$. The indications for caudal epidural nerve blocks are numerous. They have been used to treat benign pain syndromes such as diabetic polyneuropathy, post-herpetic neuralgia, complex regional pain, vertebral compression fractures and pelvic pain syndromes $(1,2,4,5,6,7,8,9)$. Other indications include surgical and obstetrical anesthesia and cancer-related pain (7). The caudal approach to the epidural space is helpful in patients who have had prior lumbar surgery, which makes the lumbar approaches more difficult (7).

From Florida Spine Institute Clearwater, Florida. *Dr. Botwin is director of Florida Spine Institute. Address correspondence: Dr. Kenneth Botwin, 2250 Drew Street, Clearwater, FL 33765.
Incorrect needle placement in caudal epidural injections occurs with relative frequency when performed without the use of fluoroscopic guidance, with a $12.5 \%$ to $38.3 \%$ incidence $(10,11,12)$. Thus, with the advent of fluoroscopy, more procedures are being performed with this method to avoid incorrect needle placement. Fluoroscopy is used in many procedures, including swallowing studies; urologic evaluations; peripheral joint injections; and, perhaps most commonly, interventional spine procedures. Fluoroscopy is one of the two types of x-ray procedures, the other being radiography. Conventional fluoroscopy, which consists of an X-ray tube located above a fixed examining table, has been widely replaced by $\mathrm{C}$-arm fluoroscopes with image intensification for use in spinal injection procedures. The $\mathrm{C}$-arm permits the physician to rotate and angle the $\mathrm{x}$-ray tube around the patient while he/ she rests on a radiolucent support table. Image intensification is achieved through the addition of an image inten- 
sifier, which receives remnant $\mathrm{x}$-ray beams that have passed through the patient and converts them into light energy, thereby increasing the brightness of the displayed image and making it easier to interpret.

To our knowledge there have been no published studies to assess the radiation exposure to the physician performing fluoroscopically guided caudal epidural injections. Studies have been performed to evaluate the risks to orthopedic surgeons using fluoroscopy $(13,14)$, cardiologists performing cardiac catheterization (15), urologists doing endourologic procedures (16) and interventional radiologists performing a variety of visceral and peripheral angiographic procedures (17). The measurement for recording exposure is the rad equivalent man (REM) or milliequivalent man (mREM), which can be measured using a dosimetry badge. The reader is referred to other more extensive reviews of radiation quantities, units and terminology $(17,18)$. These studies and ours studied exposure levels using dosimetry badges, which allow the extent of exposure to be recorded.

This study was performed to evaluate radiation exposure to a physician performing fluoroscopically guided caudal epidural steroid injections. Review of the current medical literature did not reveal any study on radiation exposure to the physician performing these procedures. This is a prospective, cohort design study of 100 fluoroscopically guided caudal epidural steroid injections performed in 100 patients with radicular pain from spinal stenosis to determine the radiation exposure to the physician performing these injections.

\section{METHODS}

One hundred consecutive patients presented to a multidisciplinary spine care practice with complaints of lower back and radicular pain. As part of a nonoperative treatment plan, patients received a combination of analgesics, anti-inflammatory medications, referral to physical therapy and fluoroscopically guided caudal epidural steroid injections.

Inclusion criteria consisted of consecutive patients who presented to the spine care center with radicular pain from herniated nucleus pulposus or lumbar spinal stenosis, which was treated with fluoroscopically guided caudal epidural steroid injections. Exclusion criteria included allergy to iodine dye or any component of the injection, and a history of prior surgery.
Procedures were performed in an ambulatory surgical center by one of seven physicians experienced in fluoroscopically guided caudal epidural injections. Similar technique was used in all reviewed procedures. Patients were placed in the prone position on a radiology table. A wedge-shaped pillow was placed under the hips to tilt the pelvis and bring the sacral hiatus into greater prominence. The sacrococcygeal area was prepared using an iodine-based antiseptic solution (Povidone Iodine, USP solution, The Clinipad Corporation, Rocky Hill, CT), and an alcohol solution (Kendall Webcol Alcohol Prep 70\% Isopropyl Alcohol, Marsfield, MA). The physician, using the sterile, gloved middle finger of the dominant hand, then localized the tip of the coccyx through palpation. In this position the area under the proximal interphalangeal joint was marked. Using a fluoroscope (Compact 7600, OEC, Salt Lake City, UT), a 22-gauge, 3.5-inch/ $90 \mathrm{~mm}$ spinal needle (Quincketype point, Luer lock, Spinocan, Becton Dickinson, Franklin Lakes, NJ) or 20-gauge, 3.5-inch/90 mm Tuohy Spinal needle (Becton Dickinson, Franklin Lakes, NJ) was guided under intermittent fluoroscopy to the midline of the sacral hiatus. A lateral fluoroscopic view was used to confirm that the needle was in the caudal epidural space. Aspirations were routinely performed. If negative for aspirate, Isovue M-300 (Iopamidol Injection, Bracco Diagnostics, Princeton, N.J.) $1 \mathrm{~mL}$ was instilled to confirm epidural flow of the injectate and to rule out intravascular, intrathecal and/or soft tissue infiltration. Once an epidurogram was obtained, a solution of $13 \mathrm{~mL}$ of $0.5 \%$ preservative-free Xylocaine (Lidocaine HCL Injection, Astra pharmaceuticals, Westborough, MA) and $12 \mathrm{mg}$ betamethasone acetate (Celestone ${ }^{\circledR}$ Soluspan $\AA$, Schering, Kenilworth, NJ) was injected. Plain radiographs in the anteroposterior and lateral views had been taken after all injections to document both the contrast pattern and needle placement.

All patients were monitored by pulse oximetry, blood pressure and ECG prior to, during, and after the procedure. Patients were transferred to the recovery unit for $40 \mathrm{~min}$ utes. All patients were seen by the physician who performed the injection and by a registered nurse prior to discharge.

All epidural injections were performed at an ambulatory care center using $\mathrm{C}$-arm fluoroscopic guidance. The $\mathrm{C}$ arm fluoroscope (OEC Compact 7600) used was operated in snapshot (pulsed-imaging) mode. X-ray voltages are measured in kilovolts peak (kVP). In the pulsed mode, a high-energy penetrating $\mathrm{X}$-ray beam was created with the 
image intensifier delivering a high $\mathrm{kVp}$ (The peak value of high-voltage generator output in the interval after a 20millisecond delay period to the end of the exposure) was based on the patient's weight and a fixed current of $8 \mathrm{~mA}$ using the snapshot mode. In this mode beam collimation constricted the $\mathrm{x}$-ray beam to the lumbar spine.

Radiation exposure was monitored using a Landauer (Glenwood, IL) dosimetry badge with a lower limit of detectability of 1 mREM. One radiographic technologist (RT) allocated four badges to physicians prior to the procedures. The badges were clearly marked as (1) outside, (2) inside, (3) ring, and (4) glasses. The "outside" badge was placed outside the lead apron worn by all the physicians, which was of $0.55 \mathrm{~mm}$ thickness (ProTech, Palm Beach Gardens, FL). The "inside" badge was placed at the shirt pocket level under the apron. The "ring" badge was placed on the ring finger of the dominant hand. The "glasses" badge was placed on the frame of lead glasses (ProTech leaded eyewear, Palm Beach Gardens, FL) that the physicians wore during the procedure. In addition, the RTs also wore a clearly marked badge outside their lead apron. A control badge was arbitrarily placed on the wall 67 inches away horizontally and 56 inches vertically, from the fluoroscopic table in the treatment room. A second control badge was also placed over 500 feet outside the fluoroscopy room to evaluate for any ambient radiation. When badges were not in use, they were all placed together with the second control badge, outside the treatment room. All RTs stood over 6 feet away from the fluoroscope. The RTs also entered into a daily log the patient's name, date of procedure, medical record number procedure level, total fluoroscopy time, voltage in $\mathrm{kVp}$, amperage in milliamps, physician performing procedure and weight of the patient.

Following all procedures the dosimetry badges were sent to Landauer for interpretation by the RT. The radiation dosimetry report from Landauer included the dose equivalent mREM (the unit of occupational radiation exposure used to monitor personnel exposure devices such as film badges) for the period in which the injections were performed. Separate readings were obtained for all badges for deep-dose, eye and shallow-dose equivalents in mREM. Deep-dose equivalent applies to external whole-body exposure and is the dose equivalent at a tissue depth of $1 \mathrm{~cm}$. Eye-dose equivalent applies to the eternal exposure of the lens of the eye and is taken as the dose equivalent at a tissue depth of $0.3 \mathrm{~cm}$. Shallow-dose equivalent applies to the external exposure of the skin or an extremity, and is taken as the dose equivalent at a tissue depth of $0.007 \mathrm{~cm}$

\section{Table 1. Patient data}

\begin{tabular}{lc}
\hline Total number patients & 100 \\
Total fluoroscopy time (seconds) & 1255 \\
Range fluoroscopy time (seconds) & $2-33$ \\
Mean age (years) & 65.72 \\
Mean weight (pounds), men & 199.4 \\
Mean weight (pounds), women & 178.5 \\
\hline
\end{tabular}

averaged over an area of $1 \mathrm{sq} \mathrm{cm}$. The total amount of mREM for each badge was obtained, and the amount of mREM per second of fluoroscopy use was calculated. All reports were reviewed and compiled by the radiographic technologist.

\section{RESULTS}

A total of 100 procedures on 100 patients (47 women and 53 men) was performed. All patients had radicular pain from lumbar spinal stenosis or herniated nucleus pulposus. The total fluoroscopy time of all 100 procedures was 125.5 seconds. The mean weight of the patients studied was 189.37 lbs. The weight range of men was 140 to $277 \mathrm{lbs}$, and the weight range of women was 110 to 379 lbs. The mean male patient weighed $199.4 \mathrm{lbs}$, and the mean female patient weighed $178.5 \mathrm{lbs}$. The mean age of patients was 65.72 years.

The mean fluoroscopy time was 12.55 seconds. The mean $\mathrm{kVp}$ received by women patients was 93.375 at $8 \mathrm{~mA}$ and 91.0769 at $8 \mathrm{~mA}$ in male patients. (See Table 1).

The exposure to the physician was calculated in mREM for all 100 procedures, from dosimetry badges. The exposure at the "outside" apron was 398 mREM (deep-dose equivalent) and at the "inside" apron was 15 mREM; "glasses” exposure was 247 mREM (eye-dose equivalent)

Table 2. Mean mREM per procedure in all 100 patients with an average fluoroscopy time of 12.55 seconds

\begin{tabular}{ll}
\hline Interventionalist, "ring" & 4.10 \\
Interventionalist, "glasses" & 2.47 \\
Interventionalist "outside" apron & 3.98 \\
Room control (inside room) & 0.22 \\
\hline
\end{tabular}


and "ring" exposure was measured to be 410 mREM (shallow-dose equivalent). The control badge which was placed inside the room 67 inches away horizontally and 56 inches vertically from the fluoroscopy table recorded an exposure of 22 mREM deep-dose equivalent. The exposure recorded from both the outside and inside dosimetry badges on the technicians and the outside room badge was 0 mREM deep-dose equivalent.

We were able to calculate the exposure per procedure using the average procedure time of 12.55 seconds to find an "outside" badge deep-dose equivalent of 3.98 mREM, a "glasses" eye-dose equivalent of 2.47 mREM a "ring" shallow-dose equivalent of $4.10 \mathrm{mREM}$ and an in-room control, deep-dose equivalent of 0.22 mREM (See Table 2).

\section{DISCUSSION}

The use of epidural steroid injections in the treatment of lumbosacral radiculopathy has become an important procedure that is both diagnostic and therapeutic. The caudal epidural injection is one of several injection techniques in which the lumbar epidural space can be accessed. The presumed ease and accessibility of the epidural space have made caudal epidural injections a favorite in specific patient populations.

Cathelin first described the procedure in 1901 (19). The introduction of midline lumbar epidural technique by Pages in 1921 caused the caudal approach to fall out of favor (20). The caudal approach was re-introduced as a technique for pain relief in childbirth by Hingson and Edwards in 1943 (21). Epidural steroid injections have been used in the treatment of lumbar radicular pain syndromes since 1952 (22-23). They were first reported in the United States in 1960 to benefit conditions causing nerve root irritation $(23,24)$. These injections were performed "blind" (without fluoroscopic guidance) using a caudal technique (24).

Table 3. General radiation exposure guides

\begin{tabular}{lc}
\hline Type of Exposure & Annual Limit \\
\hline Whole body & 5 REM/year. total \\
(head and trunk) & effective dose equivalent \\
Lens of eye & $15 \mathrm{REM} /$ year \\
Extremities & $50 \mathrm{REM} /$ year \\
Skin & $50 \mathrm{REM} /$ year \\
\hline
\end{tabular}

Modified from Reference 25.
Radiation risks to the physician and assisting personnel are evaluated using the maximum safe allowable exposure limits which have been established by the National Council on Radiation Protection and Measuring as a maximum permissible dose (25). The recommendations for occupational radiation exposure can be seen in Table 3. The current estimation of risk from radiographic exposure to a specific body part is based on the biologic effects of whole-body exposure converted by weight factors specific for individual organs and tissues. This concept was adopted by the International Commission on Radiological Protections in 1977 and was modified in 1991. Termed the effective dose equivalent, the calculation was adopted by authoritative bodies that determine radiation risks and recommend protective measures (See Table 4).

Table 4. Specific organ cancer risks of radiation (per 10,000 per Sv or per 1,000,000 per REM)

\begin{tabular}{lc}
\hline $\begin{array}{l}\text { Radiation organ or } \\
\text { cancer }\end{array}$ & $\begin{array}{c}\text { Probability of induced } \\
\text { cancer }\end{array}$ \\
\hline Breast & $50-200$ \\
Thyroid & $50-150$ \\
Lung & 50 \\
Leukemia & $15-25$ \\
Stomach & $10-20$ \\
Brain & $5-20$ \\
Colon & $10-15$ \\
Liver & $10-15$ \\
Lymphoma & $4-12$ \\
Uterus & $7-10$ \\
Salivary Glands & $5-10$ \\
Ovary & 8 \\
Bladder & $4-7$ \\
Bone & $2-5$ \\
Esophagus & $2-5$ \\
Pancreas & $2-5$ \\
Paranasal sinuses & $2-5$ \\
\hline From International Commission on Radiological Protection: Rec- \\
ommendations of the International Commission on Radiation Pro- \\
* 100 REM = 1 Sievert (Sv); 1/100 mREM $=1$ mSv. \\
\end{tabular}


When evaluating our data, it can be seen that the radiation exposure appears to be well within these regulations. If we extrapolate our data to 1000 fluoroscopically guided caudal epidural steroid injections which could be performed annually per clinician at our center, then a total radiation exposure of $4.10 \mathrm{REM}$ at the "ring" badge, 2.44 REM at the "glasses" badge and 3.88 REM at the "outside apron" badge all would fall within limits. However, depending on the volume of procedures in the physicians clinic the exposure will increase accordingly and must be followed closely. The absolute exposure to the physician must be calculated on an individual basis and must take into account that the radiation exposure will be cumulative over a lifetime.

With this in mind, leaded aprons, glasses, thyroid shields and lead barriers seem most appropriate to minimize the physician's exposure. This has also been found by other authors (26). It should be noted the long-term effects of low-dose radiation are uncertain. The exposure in our study was greatest to the hands, then eyes, of our physicians, which may argue for the use of leaded gloves in addition to leaded glasses. Also, extended tubing for administering radiographic contrast may be of benefit.

Radiation exposure results from the primary beam and scatter radiation reflected off the floor and the patient. The cardinal principles of radiation protection are: (1) maximize the distance from the radiation source; (2) use shielding materials; and (3) minimize exposure time. Technical factors using the fluoroscope may serve to reduce both occupational and patient exposure. Using pulsed imaging during fluoroscopy has been shown to reduce overall exposure by $20 \%$ to $75 \%(27,28)$. The usage of collimation also reduces unnecessary radiation exposure (28).

A radiation safety program must serve to minimize exposure to ionizing radiation while promoting safe and effective use of radiation sources in diagnosis, therapy and research. One goal of such a program is to keep the risks to radiation workers to levels that are comparable to those of other safe occupations. The pervading philosophy is that of "as low as reasonably achievable" (29).

\section{CONCLUSION}

Adhering to simple rules of radiation safety can minimize the cumulative exposure to the spinal interventionalist. These include measuring the distance between the interventionalist and the source of radiation; decreasing the overall time of exposure; and shielding susceptible areas with leaded aprons, thyroid shields, leaded glasses and leaded gloves, as well as being proficient in guiding needles under the fluoroscope. Our study demonstrates that the radiation exposure to the physician during the fluoroscopically guided caudal epidural steroid injections is well within safety guidelines.

\section{ACKNOWLEDGMENTS}

The Authors wish to thank Nicole Belsanti, RRT, Diane Hodges, RRT, and Carol Barragan, Medical Secretary for their assistance with this manuscript.

\section{REFERENCES}

1. Gardner WJ, Goebert HW, Sehgal AD. Intraspinal corticosteroids in the treatment of sciatica. Trans Am Neurol Assoc. 1961;86:215.

2. Yates DW. A comparison of the types of epidural injections commonly used in the treatment of low back pain and sciatica. Rheum Rehab 1978;17:181-186.

3. Sharma RK. Indications, techniques and results of caudal epidural injections for lumbar disc retropulsion. Postgrad Med J 1977; 53:1-6.

4. Bush K, Hillier S. A controlled study of caudal epidural injections of triamcinolone plus procaine for the management of intractable sciatica. Spine 1991; 16:572-575.

5. Mount HTR. Epidural injection of hydrocortisone for the management of the acute lumbar disc protrusion. In Morley TP (ed). Current Controversies in Neurosurgery. Philadelphia, Saunders, 1976, pp 67-72.

6. Goebert HW, Jallo SJ, Gardner WJ, et al. Painful radiculopathy treated with epidural injections of procaine and hydrocortisone acetate: Results in 113 patients. Anesth Analg 1961;140:130-134.

7. Willis RJ. Caudal epidural blockage. In Cosins MJ, Brindenbaugh DO (eds). Neural Blockage. Philadelphia, JB Lippincott, 1988, pp 376-377.

8. Waldman SD. Reflex sympathetic dystrophy. Intern Med 1990; 11:62068.

9. Waldman SD. Acute herpes zoster and postherpetic neuralgia. Intern Med. 1990; 11:33-38.

10. White AH, Derby R, Wynn G. Epidural injections for the treatment of low back pain. Spine 1980; 5:78-86.

11. Renfrew DL, Moore TE, Kathol MH. Correct placement of epidural steroid injections: Fluoroscopic guidance and contrast administration. AM J Neuroradiology 1981; 12:1003-1007, 1981.

12. Sitz and Somer. Accuracy of "blind" verses fluoroscopically guided caudal epidural injections. Spine 1999; 24:1371-1376.

13. Giachino AA, Cheny M. Irradiation of the surgeon during pinning of femoral fractures. JBJS 1980; 62:227229. 
14. Miller ME, Davis ML, MacClean CR et al. Radiation exposure and associated risks to operating room personnel during use of fluoroscopic guidance for selected orthopedic surgical procedures. JBJS 1983; 65-A:1-4.

15. Miller, SW, Castrovovo FP. Radiation exposure and protection in cardiac catheterization Laboratories. $A J$ Cardiology 1985; 55:171-176.

16. Giblin JG, Rubenstein J, Taylor A et al. Radiation risk to the urologist during endourologic procedures, and a new shield that reduces exposure. Urology 1996; 48:624-627.

17. Gruber RD, Botwin KB, Shah CP. Radiation Safety for the Physician. Pain Procedures in Clinical Practice, ed. 2, Hanley and Belfus 2000, p 25.

18. Wycoff HO. The international system of units. Radiology 1978; 128:833-835.

19. Cathelin MF. Une nouvelle voie d'injection rachidienne. Methode du injections epidurales pas le procedue du canal sacre. D R Soc Biol 1901; Par 53:452.

20. Pages E. Anestesia metamerica. Rev Sanid Mil Madr 1921; 11:351-380.

21. Hingson RA, Edwards WB. An analysis of the first ten thousand confinements managed with continuous causal analgesia with a report of the authors' first one thousand cases. JAMA 1943; 125:538.

22. Robechhi A, Capra R. L'idrocotisone (composto F), Rime esperinze cliniche in campo reumatologico,
Minerva Med 1952; 98:1259-1263.

23. Benzon H. Epidural steroid injections for low back pain and lumbosacral radiculopathy. Pain 1986; 24 : 277-295.

24. Brown JH. Pressure caudal anesthesia and back manipulation. Northwest Med 1960; 59:905-909.

25. National Council on Radiation Protection and Measurements. Ionizing Radiation Exposures of the Population of the United States. Report No. 116, Washington, DC, NCRP, 1993.

26. Marx VM, Niklason L, Mauge EA. Occupational radiation exposure to the interventional radiologist: A prospective study: JVIR 1993; 3:597-606.

27. Adelstein SJ. Uncertainty and relative risks of radiation exposure. JAMA 1987; 258:655-657.

28. Hernandez RJ, Goodsitt MM. Reduction of radiation dose in pediatric patients using pulsed fluoroscopy. Am J Roentgerol 1996;167:1247-1253.

29. National Council on Radiation Protection and Measurements. Implementation of the Principle of as Low as Reasonable Achievable (ALARA) for Medical and Dental Personnel. NCRP Report no. 107. Bethesda, MD, NCRP, 1990.

30. International Commission on Radiological Protection. Recommendation of the International Commission on Radiation Protection 26. Ann Int Commission Radiat Prot 1977; 1:1-53. 